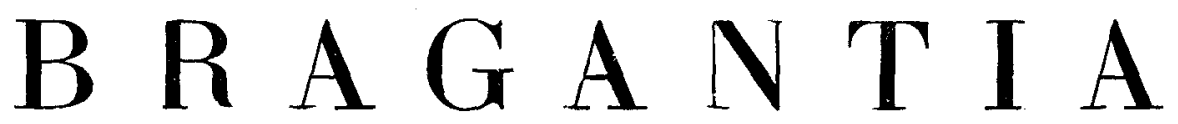

Boletim Cientifico do Instituto Agronômico do Estado de S. Paulo

Vol. 29

Campinas, junho de 1970

N. ${ }^{\circ} 18$

\title{
ADUBAÇÃO DO MILHO
}

XXVI - ENSAIOS COM DIVERSOS FOSFATOS (9. ${ }^{a}$ SERIE) ( $\left.{ }^{1}\right)$

G. P. ViÉGas, Luiz T. DE Miranda, engenheiros-agrônomos, Seção de Cereais, e E. S. FREIRE, engenheiro-agrônomo $\left({ }^{2}\right)$, Instituto Agronômico

\section{SINOPSE}

Quatro ensaios de adubação do milho com diversos fosfatos na presença de NK foram conduzidos em 1961-62, em diferentes localidades do Estado de São Paulo.

No conjunto dos quatro ensaios e dos seis fosfatos estudados, as doses de 60 e $120 \mathrm{~kg} / \mathrm{ha}$ de $\mathrm{P}_{2} \mathrm{O}_{5}$ total proporcionaram aumentos de, respectivamente, 24 e 35 por cento. Em méđia das duas doses, o aumento devido ao superfosfato simples correspondeu a $1030 \mathrm{~kg} / \mathrm{ha}$ de grãos. Atribuindo-se valor 100 a êsse aumento, os indices referentes aos outros fosfatos seriam: superfosfato triplo, 98; fosfato bicálcico, 71 ; fosfato Alvorada, 51; fosforita de Olinda, 50; apatita de Araxá, 40.

\section{1 - INTRODUÇÃO}

Em continuação aos artigos publicados anteriormente, sôbre a eficiência de vários fosfatos para a adubação do milho (1, 3-9), neste trabalho são apresentados os resultados de mais quatro experiências, conduzidas em 1961-62, nas quais superfosfato simples foi comparado com superfosfato triplo, fosfato bicálcico, fosforita de Olinda, fosfato Alvorada e fosfato de Araxá.

( $\left.{ }^{1}\right)$ Recebido para publicação em 6 de fevereiro de 1970. $\left(^{2}\right)$ Contratado pelo Conselho Nacional de Pesquisas, para colaborar com
técnicos do Instituto Agronómico. Sua colaboração no presente trabalho foi p*estada na apresentação e interpretação dos resultados obtidos. 


\section{2 - MATERIAIS E METODOS}

Em blocos ao acaso, com quatro repetições, foram estudados os seguintes tratamentos:

1) $\mathrm{NK}$ + dose 1 de superfosfato simples

2) $\mathrm{NK}+$ dose 2 de superfosfato simples

3) NK + dose 1 de superfosfato triplo

4) NK + dose 2 de superfosfato triplo

5) NK + dose 1 de fosfato bicálcico

6) $\mathrm{NK}+$ dose 2 de fosfato bicálcico

7) $\mathrm{NK}+$ dose 1 de fosforita de Olinda

8) NK + dose 2 de fosforita de Olinda

9) $\mathrm{NK}+$ dose 1 de fosfato Alvorada

10) NK + dose 2 de fosfato Alvorada

11) NK + dose 1 de apatita de Araxá

12) NK + dose 2 de apatita de Araxá

13) NK

14) Sem adubo

De $\mathrm{N}$ e $\mathrm{K}_{2} \mathrm{O}$ foram usados, respectivamente, 60 e $30 \mathrm{~kg} / \mathrm{ha}$, nas formas de sulfato de amônio e cloreto de potássio. As doses 1 e 2 de fertilizantes fosfatados corresponderam a, respectivamente, 60 e $120 \mathrm{~kg} / \mathrm{ha}$ de $\mathrm{P}_{2} \mathrm{O}_{5}$ total.

As doses totais de fósforo e potássio e $25 \%$ da dose de nitrogênio foram aplicados nos sulcos de plantio, pouco antes da semeação, que foi efetuada em pequenos sulcos abertos em um dos taludes dos sulcos adubados. A parte restante da dose de nitrogênio foi empregada em cobertura, cêrca de quarenta dias depois do plantio.

Os canteiros tiveram cinco fileiras de $10 \mathrm{~m}$ de comprimento: espaçadas de $1 \mathrm{~m}$, e aproveitaram-se sòmente as três fileiras centrais, ou seja, $30 \mathrm{~m}^{2}$. A distância entre as covas da mesma fileira foi de $40 \mathrm{~cm}$. Cada cova recebeu quatro sementes, para ficarem duas plantas no desbaste. Usaram-se sementes do híbrido $\mathrm{H}-6999$.

Segundo o plano descrito, conduziram-se, em 1961-62, quatro experiências nos seguintes locais $\left(^{3}\right)$ :

$\left.{ }^{3}\right)$ Os autores agradecem as facilidades proporcionadas e a colaboracão prestada pelos irmãos Amorim, Promisstio; pelo Sr. L de Paula Machado, Rio Claro; pelo Fng.o-Agr.a Eli de Araújo Sonza, Botucatu, e pelo Eng.o-Agr.o A. Gentil Gomes, Pindamonhangaba. 
1) Sítio Amorim, município de Promissão. A experiência foi instalada em solo Latossolo Vermelho Escuro, fase arenosa, segundo a classificação do Serviço Nacional de Pesquisas Agronômicas (2).

2) Fazenda São José, do Haras São José, município de Rio Claro, em solo Latossolo Vermelho (2).

3) Estação Experimental de Botucatu, do Ministério da Agricultura, em solo Latossolo Roxo (2).

4) Haras Paulista, município de Pindamonhangaba, em solo do Terciário.

$\mathrm{Na}$ relação que se segue são apresentados os resultados das análises químicas ( $\left.{ }^{4}\right)$ de amostras de solo das áreas aproveitadas para três das quatro experiências:

Promissão Rio Claro Botucatu

\begin{tabular}{|c|c|c|}
\hline $\mathrm{pH}$ internacional & 4,50 & 5,10 \\
\hline $\mathrm{N} \% \quad \ldots \ldots$ & 0,05 & 0,17 \\
\hline $\mathrm{PO}_{4}-3\left({ }^{5}\right)$ & 0,06 & 0,44 \\
\hline $\left.\mathrm{K}+\mathrm{C}^{6}\right)$ & 0,12 & 0,28 \\
\hline $\mathrm{Ca}+2\left({ }^{6}\right)$ & 1,60 & 2,20 \\
\hline
\end{tabular}

O plantio das experiências foi efetuado no decorrer de novembro de 1961 ; a colheita, 5,5 meses depois.

\section{3 - RESULTADOS}

Nas localidades em que foram conduzidas as experiências, as chuvas caídas aproximaram-se das normais da época até fevereiro; em março, porém, ultrapassaram essas normais. -

Os "stands" foram geralmente satisfatórios e suficientemente uniformes, exceto no tratamento NK da experiência de Promissão, no qual o "stand" inicial foi um pouco mais baixo e o final cor-

\footnotetext{
( $\left.{ }^{4}\right)$ Análises efetuadas na Seção de Química Mineral, Instituto Agronômico.

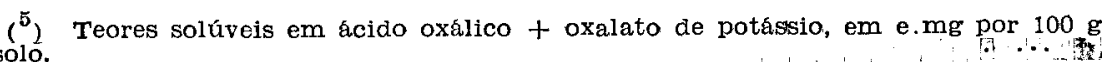

( $\left.{ }^{6}\right)$ Teores trocáveis, em e.mg por $100 \mathrm{~g}$ de solo.
} 
respondeu a cêrca da metade dos registrados nos demais tratamentos. Provàvelmente, isso foi conseqüência da adição de nitrogênio e potássio a solo altamente deficiente de fósforo, agravada pela aplicação do nitrogênio na forma de sulfato de amônio, pois o solo era fortemente ácido.

As produções obtidas nas experiências são apresentadas no quadro 1.

As variâncias residuais das experiências individuais oscilaram entre limites que permitiram analisar estatìsticamente as produções do conjunto das quatro experiências.

Nesse conjunto, o coeficiente de variação foi de $23,7 \%$. Em relação ao tratamento sem adubo, o efeito de NK não foi significativo. Também não alcançou significância a interação NK $\times$ sem adubo $\times$ localidades.

Em média das doses 1 e 2 de fósforo e dos diversos fosfatos estudados, o efeito do fósforo foi significativo ao nível de $5 \%$ de probabilidade e correspondeu a $+704 \mathrm{~kg} / \mathrm{ha}$ de grãos $(+30 \%)$. $A$ interação $\mathrm{P} \times \mathrm{NK} \times$ localidades também foi significativa ao nível de $5 \%$. Efetivamente, embora positivo em tôdas as experiências, na de Botucatu o efeito médio do fósforo foi muito pequeno $(+7 \%)$ e não alcançou significância.

Quando se passou da dose 1 para a dose 2, o efeito do fósforo cresceu significativamente de +571 para $+836 \mathrm{~kg} / \mathrm{ha}$ (de +24 para +35 por cento). A interação entre essas doses e as localidades não foi significativa.

No conjunto das experiências e segundo o teste $F$, houve diferenças significativas, ao nivel de $5 \%$, entre os fosfatos considerados, e a interação formas de fósforo $\times$ localidades não foi significativa. Entretanto, de acôrdo com o teste de Tukey ao nível de $5 \%$, as produçóes ( $V$. penúltima coluna do quadro 1 ) proporcionadas pelas adubaçōes que receberam a dose 1 dos diversos fosfatos, embora variassem muito, não diferiram estatìsticamente. O mesmo aconteceu no caso da dose 2 e no da média das doses 1 e 2 .

Em relação à produção obtida com NK e segundo o teste de Tukey a $5 \%$, os efeitos da dose 1 dos diversos fosfatos não alcançaram significância e os da dose 2 só foram significativos quando esta dose foi empregada sob as formas de superfosfato simples ou superfosfato triplo. 


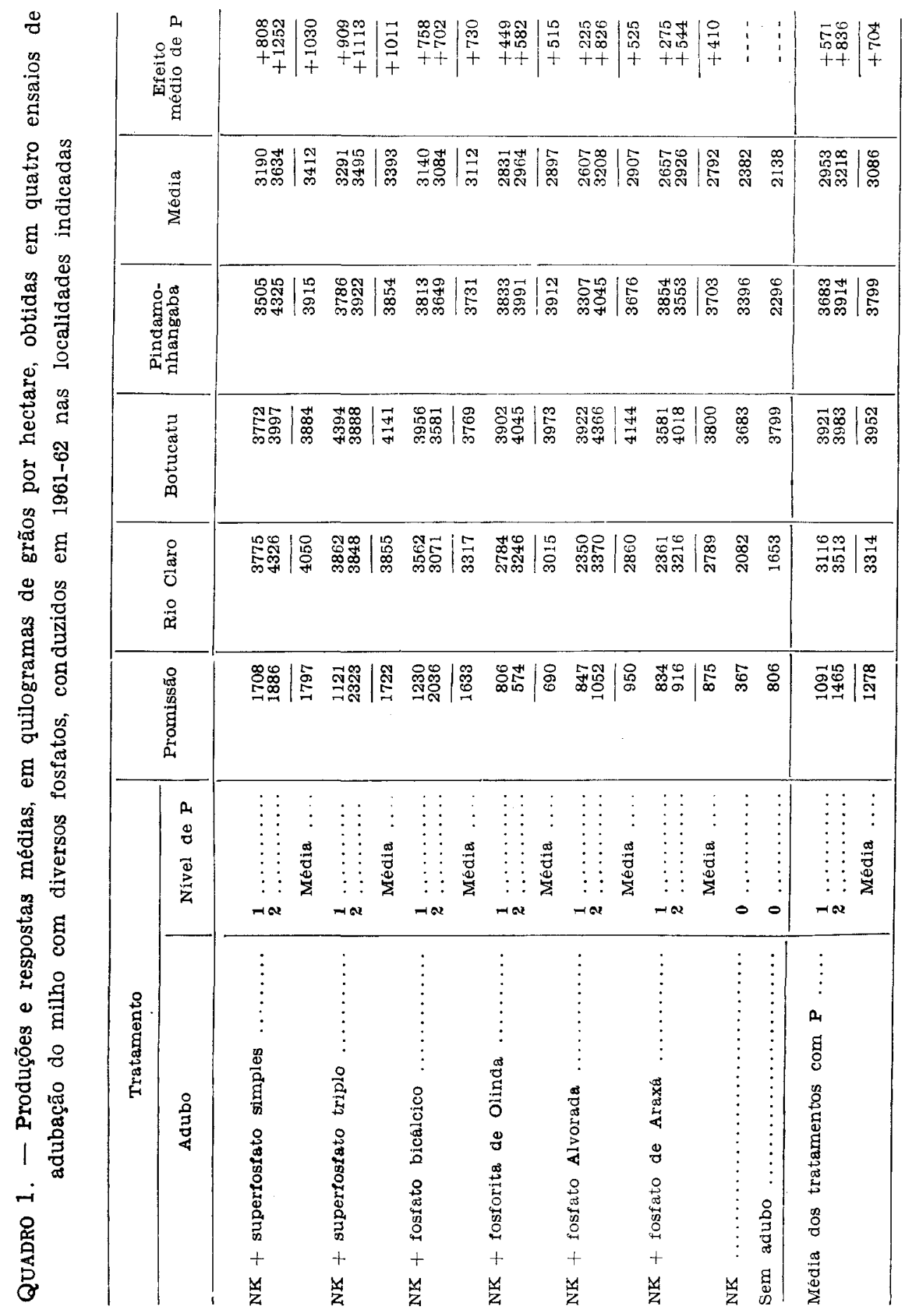


Na última coluna do quadro 1 são apresentados os aumentos de produção proporcionados pelos diferentes fosfatos. Atribuindo-se valor 100 à média dos efeitos das doses 1 e 2 de superfosfato simples, seriam os seguintes os indices referentes aos fosfatos comparados: superfosfato triplo, 98; fosfato bicálcico, 71 ; fosfato Alvorada, 51; fosforita de Olinda, 50 ; apatita de Araxá, 40.

Nas experiências de Promissão e Botucatu obtiveram-se informações que, embora sumàriamente, são apresentadas a seguir.

Na de Promissão, o índice de espigas (número de espigas por 100 plantas ) foi de 41, nos canteiros adubados com NK, e elevou-se a 50 e 66, respectivamente, em média dos que, em adição a NK, receberam fosfatos de rocha ou fosfatos solúveis.

Por ocasião da colheita, havia $4 \%$ de plantas acamadas no tratamento $\mathrm{NK} ; 3 \%$, em média dos que receberam fosfatos de rocha; e $4 \%$, nos adubados com fosfatos solúveis. A adição de fosfatos de rocha ou fosfatos solúveis reduziu de $4 \%$ para $2 \%$ a proporção de plantas quebradas abaixo da inserção das espigas. No tratamento NK e nos que receberam fosfatos de rocha ou fosfatos solúveis, as proporções de espigas atacadas por moléstias foram de, respectivamente, 11,7 e 6 por cento.

Em Botucatu, nos canteiros adubados com NK e nos que, adicionalmente, receberam fosfatos de rocha ou fosfatos solúveis, os indices de espigas foram de, respectivamente, 87,87 e 88 . Tendo ocorrido forte ventania cêrca de dois meses depois da floração, as proporções de plantas quebradas abaixo da inserção das espigas se elevaram a 13,17 e 19 por cento, respectivamente, nos tratamentos que receberam $\mathrm{NK}$, fosfatos de rocha e fosfatos solúveis; em compensação, o número de plantas acamadas correspondeu a, respectivamente, 7,5 e 4 por cento. A porcentagem de espigas atacadas por moléstias passou de $2 \%$, nos canteiros adubados com NK, para $3 \%$ e $5 \%$, respectivamente, nos adubados com fosfatos de rocha ou fosfatos solúveis. Tendo-se anotado a data do florescimento em cada canteiro, pôde-se verificar que, em relação ao tratamento $\mathrm{NK}$, as adubações com fosfatos de rocha e fosfatos solúveis provocaram antecipaçōes mécias de, respectivamente, dois e cinco dias, no pendoamento, e de um e cinco dias, no embonecamento. 


\section{4 - CONCLUSÕES}

Das experiências relatadas, nas quais o superfosfato simples foi comparado com diversos fosfatos na presença de $\mathrm{NK}$, em quatro localidades do Estado de São Paulo, podem-se tirar as seguintes conclusōes gerais:

a) Em média das quatro experiências e dos seis fosfatos estudados, os aumentos proporcionados pelas doses de $60 \mathrm{e}$ $120 \mathrm{~kg} / \mathrm{ha}$ de $\mathrm{P}_{2} \mathrm{O}_{5}$ total corresponderam a, respectivamente, $24 \mathrm{e}$ 35 por cento da produção obtida sòmente com NK.

b) Em média das duas doses e das quatro experiências, o aumento devido ao superfosfato simples foi de $1030 \mathrm{~kg} / \mathrm{ha}$ de grãos. Atribuindo-se valor 100 a êsse aumento, os índices referentes aos outros fosfatos seriam: superfosfato triplo, 98 ; fosfato bicálcico, 71 ; fosfato Alvorada, 51 ; fosforita de Olinda, 50 ; apatita de Araxá, 40.

FERTILIZER EXPERIMENTS WITH CORN

XXVI - TRIALS WITH VARIOUS PHOSPHORUS SOURCES (9th SERIES)

\section{SUMMARY}

Four experiments comparing six phosphate fertilizers for the production of corn were conducted in 1961-62 at different localities of the State of São Paulo.

As an average of the four trials and the six phosphates, the yield increases due to the doses of 60 and $120 \mathrm{~kg} / \mathrm{ha}$ of total $\mathrm{P}_{2} \mathrm{O}_{5}$ corresponded to 24 and 35 per cent, respectively. The average increase due to ordinary superphosphate was $1030 \mathrm{~kg} / \mathrm{ha}$ of grain. Giving the value 100 to this increase, the relative efficiencies of the other phosphates were: triple superphosphate, 98; dicalcium phosphate, 71; "Alvorada" phosphate, 51; "Olinda" phosphate, 50; "Araxá" phosphate, 40; The last three phosphorus sources are local rock phosphates.

\section{LITERATURA CITADA}

1. GOMES, A. GENTIL; CATANI, R. A. \& FREIRE, E. S. Adubação do milho. XIX - Ensaios com diversos fosfatos (5. ${ }^{\text {a série). }}$ Bragantia 20:35-41, 1961. 
2. SERVIÇO NACIONAL DE PESQUISAS AGRONÔMICAS. COMISSĀO DE SOLOS. Levantamento de reconhecimento dos solos do Estado de São Paulo. Rio de Janeiro, Ministério da Agricultura, 1960. 634p. (Boletim 12)

3. VIÉGAS, G. P.; FREIRE, E. S. \& CONAGIN, A. Adubação do milho. XVIII - Ensaios com diversos fosfatos (4. a série). Bragantia 20:15-34, 1961.

4.

\& SCHMIDT, NELSON C. Adubação do milho. XXII - Ensaios com diversos fosfatos (8. ${ }^{a}$ série). Bragantia 20:537-545, 1961.

5 . \& VENTURINI, W. R. Adubação do milho. $\mathbf{X V}$ - Ensaios com diversos fosfatos (1.a série). Bragantia 19:943-959, 1960.

6. \& Adubação do $\mathrm{milho}$. XVI - Ensaios com diversos fosfatos (2.a série). Bragantia 19:997-1009, 1960.

7. \& - Adubação do milho. $\mathrm{XX}$ - Ensaios com diversos fosfatos (6. ${ }^{\mathrm{a}}$ série). Bragantia 20:389-402, 1961 .

8.

$\&$

Adubação do milho. XXI - Ensaios com diversos fosfatos (7.a série). Bragantia 20:461-470, 1961 .

9.

XVII -, SMITH, E. \& FREIRE, E. S. Adubação do milho. 20:1-13, 1961. 